\title{
Transformações do capitalismo e formação do indivíduo: contribuições da Escola de Frankfurt na análise das eleições presidenciais nos EUA e Brasil ${ }^{\star}$ Gustavo Henrique Carretero $\mathbb{1}^{\star} \star \star$ Pontificia Universidade Católica de São Paulo, São Paulo, SP, Brasil Resumo
}

\begin{abstract}
O artigo teve como referencial teórico as contribuições dos autores da primeira geração da Escola de Frankfurt. Ele visa apresentar, em termos gerais, as alterações que ocorreram no capitalismo nos séculos XIX e XX e os impactos delas na formação do indivíduo - ainda percebidos na contemporaneidade. Para tanto, são apresentadas características do capitalismo liberal e monopolista, assim como da ideologia produzida por tais configurações desse sistema produtivo. A partir disso, é destacado como tais elementos incidem na formação do indivíduo e como há alterações em sua função social: da oposição para a adesão. Para tanto, são analisados alguns fenômenos psicossociais ocorridos nas últimas eleições presidenciais nos EUA e no Brasil. Se algumas proposições da primeira geração da Escola de Frankfurt se tornam anacrônicas, quanto aos meios, as contribuições a respeito da manipulação da massa se tornam extremamente atuais. A redução de indivíduos a algoritmos, passíveis de manipulação, demonstra a falência do modelo de individualidade burguês. Longe de ser uma referência nostálgica ao modelo liberal de indivíduo, o artigo visa demonstrar as contradições da formação do indivíduo na contemporaneidade.
\end{abstract}

Palavras-chave: capitalismo liberal; capitalismo monopolista; ideologia; formação do indivíduo; Escola de Frankfurt.

\section{Capitalism's transformations and individual's formation: contributions of the Frankfurt School in the analysis of the presidential elections in the USA and Brazil Abstract}

This paper has as theoretical reference the contributions of the authors of the first generation of the Frankfurt School. It aims to present the changes occurred in capitalism in the XIX and XX centuries and their impact in individual's formation - still noticed nowadays. Therefore, characteristics of the liberal and monopoly capitalism are presented, as well as the ideology produced by such configurations of the production system. From this, it is highlighted as these elements affect the formation of the individual and how there are changes in its social function: opposition to adhesion. In order to do so, it has been analyzed some psychosocial phenomena that occurred in the last presidential elections in the USA and Brazil. If some propositions of the first generation of the Frankfurt School become anachronistic, as to the means, the contributions regarding mass manipulation become extremely actual. The reduction of individuals to algorithms demonstrates the bankruptcy of the model of bourgeois individuality. Far from being a nostalgic reference to the liberal model of individual, the article aims to demonstrate its contradictions in the contemporary world.

Keywords: liberal capitalism; monopoly capitalism; ideology; individual's formation; Frankfurt School.

O presente artigo visa destacar alguns elementos acerca das transformações do capitalismo em seu processo histórico. São utilizadas as reflexões da primeira geração da Escola de Frankfurt, dando ênfase, especialmente à formação do indivíduo e alterações na ideologia a respeito dele. Vale destacar que a obra Capitalismo monopolista: ensaio sobre a ordem social americana, de Baran e Sweezy (1966), é utilizada como suporte para tal discussão. Os autores não fazem parte da primeira geração da Escola de Frankfurt. Optou-se por tal procedimento com a finalidade de facilitar a compreensão dos leitores a respeito dos processos sociais analisados pelos frankfurtianos.

O Capitalismo não se manteve homogêneo e inalterado desde seu aparecimento e implantação pela burguesia. Observam-se, durante a história, diversas fases, concepções e ideologias que sustentaram a implantação e manutenção deste sistema. Todavia, para o artigo é interessante fazer a contraposição entre o capitalismo liberal e o capitalismo tardio ou monopolista. Nesta sucinta reflexão não serão aprofundados, dentre outros temas, nem os aspectos histó-

\footnotetext{
^ Pesquisa financiada pela CAPES

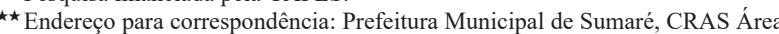
Cura. Rua Deusdete Alves, 206, Parque Santo Antônio - Sumaré, SP - Brasil. CEP: 13173343.E-mail: psycogus@hotmail.com

Os dados completos do autor encontram-se ao final do artigo.
}

ricos que possibilitaram as transformações no capitalismo, nem o longo processo de ascensão, conquista e dominação dos ideais burgueses. Entretanto, apresentar-se-ão características gerais das duas formas do capitalismo, quando em funcionamento pleno na sociedade ocidental.

A subida da burguesia ao poder provocou profundas alterações nas esferas econômica, política, cultural e formas de socialização da sociedade. Os autores da primeira geração da Escola de Frankfurt afirmam que a concepção de subjetividade como conhecida na atualidade é fruto do mundo burguês (ADORNO, 1991; HORKHEIMER, 2010), podendo ser encontrados elementos do protótipo do indivíduo burguês já no período clássico grego, como na Odisseia de Homero (HORKHEIMER, 2010; ADORNO, 1985).

As revoluções burguesas culminaram na tomada do poder por tal classe social pelo solapamento da antiga ordem. Não se deve pensar que tal processo iniciou-se economicamente. Percebe-se que, com a chegada de tal classe ao poder, a esfera da produção torna-se o principal fundamento da existência humana. O surgimento, ascensão e conquista do poder pela burguesia ocorreu durante vários séculos. Os Renascimentos Cultural e Comercial da Europa podem ser datados como o surgimento da classe e início da derrocada da ordem feudal. Vários even- 
tos históricos colaboraram e resultaram do esforço de tal classe para o estabelecimento de sua ordem social; dentre outros podem ser destacados: a Reforma Protestante no século XVI, o surgimento do método científico e do Iluminismo nos séculos XVII e XVIII; a Revolução Gloriosa no século XVII; a Revolução Francesa e a Revolução Industrial no século XVIII.

Para refletir sobre as profundas alterações sociais promovidas pela burguesia é necessário destacar os aspectos ideológicos que perpassam tal processo. Assim, apresentar características do sistema político e econômico imposto por essa classe sem destacar os aspectos ideológicos seria ingênuo, senão incorreto. No século XIX houve o apogeu do liberalismo, sendo que em suas últimas décadas acentuaram-se as transformações no sistema capitalista, que culminaram com o surgimento de novas configurações do sistema produtivo.

\section{1 - Características e ideologia do capitalismo em sua forma liberal e monopolista}

\section{A. Capitalismo Liberal}

Baran e Sweezy (1966) destacam que a burguesia, nos seus primórdios, era formada por centenas de empreendedores individuais que usavam de sua riqueza para fazer fortunas. Inicialmente, tal processo se dava pelo comércio, venda de produtos raros na Europa comprados por valores irrisórios ou trocas altamente vantajosas. Novas forma de obtenção de lucro se abriram com a Revolução Industrial, que possibilitou que o excedente, ou mais valia, fosse obtido por meio da produção de mercadorias. Os custos de produção abriam possibilidade de venda a valores maiores do que a importação.

Nesse contexto surgem milhares de pequenas empresas que produzem para um mercado em expansão. O preço do produto é imposto pela concorrência com diversas outras pequenas empresas que produzem no mesmo setor. A tentativa de inovação tecnológica é buscada como forma de solapar toda concorrência e se constitui como meta na disputa entre pequenas firmas que produzem para um mercado anônimo.

Os autores destacam que o excedente, nessa modalidade do capitalismo, é absorvido por meio do consumo e da acumulação. Tal excedente seria obtido pela exploração do trabalho de milhares de homens, mulheres e crianças expulsos dos campos e que migraram para as cidades com a derrocada da ordem feudal. Tais populações se constituíram como mão de obra desqualificada e, portanto, barata.

Marcuse (1973) destaca que a liberdade de empreendimento não foi vantajosa para toda a sociedade. Ela significou, para os trabalhadores, a "liberdade" de trabalhar ou morrer à míngua. A liberdade de empreendimento tornou-se, portanto, labuta (trabalho sem sentido), insegurança e temor para a maioria da população. Os trabalhadores explorados eram obrigados a assumir a condição de sujeitos econômicos livres, apesar de não terem condições para tal. Eles foram submetidos à concorrência em contraste com as formações "coletivistas" feudais.
Dois aspectos fundamentais da ideologia liberal são: 1. liberdade política, econômica e intelectual (MARCUSE, 1973); 2. igualitarismo ideológico de oportunidades, nas quais as desigualdades não seriam frutos de instituições injustas, mas dotes pessoais superiores e inferiores (BARAN; SWEEZY, 1966).

Para Marcuse (1973) a liberdade de pensamento, de palavra e de consciência ajudou a promover uma das características mais marcantes do período liberal: o livre empreendimento. Este foi um dos baluartes do sistema, possibilitando o surgimento da figura do empresário individual (BARAN; SWEEZY, 1966), que, por meio da acumulação de riquezas granjeadas no mercado, pela livre iniciativa e enfrentamento de riscos, procurava os maiores lucros possíveis.

Marcuse (1998a) afirma que (na passagem do capitalismo liberal ao monopolista) o processo de produção de mercadorias solapou a base econômica sobre a qual a racionalidade individualista se constituiu e se assentava. Além disso, a formação de indivíduos no modelo liberal se torna anacrônica no modo de produção monopolista. Se as mercadorias são produzidas em massa e para as massas não há a necessidade social de indivíduos pensantes, autônomos e críticos. Crochik (1998) ressalta que cada sociedade "produz" indivíduos necessários à sua reprodução.

Pode-se falar, nesse momento, de uma nova configuração do sistema capitalista que assume diversas nomenclaturas, tais como: capitalismo tardio, sociedade industrial avançada, capitalismo monopolista, sociedade administrada. Tais transformações do sistema produtivo designam alterações profundas na organização social, política, econômica. Tais transformações minam as bases de uma das mais ilustres "invenções" possibilitadas pela ideologia burguesa: o indivíduo como portador de razão e autonomia e capaz de opor-se à sociedade na defesa de seus interesses racionais.

A mecanização e racionalização da produção levaram o competidor mais fraco a submeter-se ao domínio de grandes empresas da indústria mecanizada. Isso abole o sujeito econômico livre. Com o surgimento do capitalismo monopolista, a ideia de indivíduo torna-se ambígua: de um lado está a insistência no desempenho social livre e eficiência produtiva e do outro a massificação da produção, do trabalho, dos produtos e da subjetividade (MARCUSE, 1998a). Os direitos e liberdades individuais passam a ser interpretados no âmbito da privacidade e afastamento da sociedade, perdendo assim seu caráter social e tornando-se particular.

\section{B. Capitalismo Monopolista}

Baran e Sweezy (1966) destacam que o capitalismo monopolista se caracteriza pelo predomínio de grandes empresas que produzem em grande escala. A essas cabe uma parcela significativa da produção de uma indústria (ramo de produção) ou mesmo várias. Tais empresas são capazes de controlar os preços, tipos e volumes de investimento.

O termo monopolista não designa exclusividade, mas oligopólio, ou seja, poucos produtores dominando o mercado e produtos que se substituem um ao outro de forma 
mais ou menos satisfatória. Tal elemento levou à derrocada da concorrência e estabilização dos preços em certos patamares. Uma das consequências desse processo é a perda da importância da pequena empresa, que continua existindo, mas com menor relevância e sem potencial de exercer iniciativas próprias e independentes.

Para Baran e Sweezy (1966), no capitalismo monopolista o tipo sociológico representado pelo empresário individualista (preocupado exclusivamente com seus interesses e os de sua família) é substituído pelos administradores (que defendem os interesses da empresa). Em outras palavras, do dominador da instituição para o dominado pela instituição. O caráter pessoal no controle das empresas é substituído pelo da administração e/ou da Sociedade Anônima (S. A.), que possui três características: 1. controle nas mãos de uma junta de diretores e principais funcionários executivos (o poder real não está nas mãos de quem administra a empresa); 2. a administração se dá por um grupo que se autoperpetua; 3 . a empresa busca atingir independência financeira pela criação interna de fundos que permanecem à disposição da administração.

Os oligopólios conseguiram uma crescente independência tanto em relação aos banqueiros como aos acionistas dominantes. Suas políticas ligaram-se, em proporções cada vez maiores, aos seus próprios interesses, ao invés de subordinar-se às conveniências de um grupo.

Com isso, na figura dos administradores se dá um processo de mediação entre os interesses individuais e os da empresa: na medida em que a empresa avança, o indivíduo seria recompensado, confundindo-se o progresso da instituição com o pessoal. Tais elementos acabam por se tornar as finalidades e valores subjetivos do mundo dos negócios, porque são as exigências do sistema. $\mathrm{O}$ caráter deste determina a psicologia dos seus membros, e não o inverso.

O verdadeiro capitalista no sistema monopolista não é o empresário individual, mas as empresas. Estas são uma versão ampliada e institucionalizada do capitalista pessoal. Elas possuem um horizonte temporal mais amplo e são calculadores mais racionais, pela racionalização da administração. As empresas transformam-se em tecnocracias, assumindo características próprias nas mãos da administração interna. Elas visam, portanto, à redução de custos, expansão da receita e aumento dos lucros para a instituição. Tais transformações têm impacto nos processos de subjetivação, pois há a substituição de indivíduos com racionalidade e interesse próprio por instituições com tais características, devendo os homens se submeter a tais pressupostos (BARAN; SWEEZY, 1966; HORKHEIMER, 2010).

Nessa nova organização do capitalismo, a transformação tecnológica assume papel crucial. Segundo Marcuse (1998a), a eficiência produtiva torna-se fundamental e favorece empresas com o equipamento industrial mais altamente mecanizado, racionalizado e avançado. Esse processo de acumulação do poder tecnológico favorece a concentração do poder econômico, com a formação de enormes empresas associadas. Tal conglomerado empresarial forma um aparato (instituições, dispositivos e orga- nizações da indústria em sua situação social dominante) que dita em larga escala a quantidade, a forma e o tipo de mercadorias a serem produzidas. Assim, segundo Marcuse (1973), a tecnologia serve à fusão da economia, política, cultura e racionalidade. A tecnologia acaba por se tornar totalitária por determinar não apenas as oscilações, habilidades e atitudes socialmente necessárias, mas também necessidades e aspirações individuais. A existência privada dos homens é invadida pela pública, invalidando tal contraposição e transformando necessidades sociais em individuais. Dessa maneira, a tecnologia serve para produzir novas e mais eficazes formas de controle e coesão social, ao mesmo tempo em que fica exposta a falácia da noção de "neutralidade" da tecnologia.

Baran e Sweezy (1966) defendem que o capitalismo monopolista é uma resposta ao alto grau de excedente econômico produzido pela sociedade e que não seria passível de investimento. Eles defendem que os mercados não tinham mais a possibilidade de absorção do excedente produzido. Dessa forma, o excedente obtido no capitalismo liberal pela exploração de mão de obra, consumo e acumulação teve que encontrar novas formas de ser produzido na nova configuração do sistema. Os autores destacam três estratégias para produção de excedente: campanhas de venda, Estado ou Governo e militarismo com imperialismo.

A tecnologia, como já referido, tem papel fundamental no investimento e aumento do excedente, pelas campanhas de vendas. Novos métodos de produção e novos produtos aumentam o lucro, acentuando o caráter da busca dirigida, lucrativa e institucionalizada pela novidade. A procura da invenção de novos produtos é constante, mas com limitações. Assim, as campanhas de vendas são uma das estratégias criadas para a manutenção do consumo em certa escala. Outra estratégia é a obsolescência planejada, ou seja, alterações mínimas de produtos, variação de aspectos e embalagem, modificação de modelo. A obsolescência planejada visa à criação de novas necessidades de consumo a fim de serem sanadas por "novos" produtos. Tal processo segue infinitamente, contendo em si uma lógica perversa: escondendo a ausência de novidades no mecanismo. Esse processo também gera o alheamento dos indivíduos de suas necessidades pela imposição de novas, relacionadas ao consumo.

Os autores defendem que a publicidade é produto do capitalismo monopolista e procura envolver os produtos de certas características. Ela é, portanto, resultado da decadência da concorrência e leva os consumidores a fazerem escolhas por motivos irracionais. A publicidade mantém o sistema pela expansão do consumo, tendo em vista a tendência deste à estagnação.

O Estado, segundo Baran e Sweezy (1966), tem a finalidade de servir aos interesses do capital monopolista, por meio da absorção de grande parte do excedente, direta ou indiretamente. Os usos que o governo faz do excedente está determinado por interesses do sistema monopolista e, com o passar do tempo, tal procedimento se torna cada vez mais irracional e destrutivo. Destaca-se que, na forma como o capitalismo monopolista se organiza, os meios privados não têm a capacidade de absorver todo o excedente 
produzido. Dessa maneira, os Estados nacionais transformam-se em geradores de renda. Além disso, a necessidade de dinheiro para a manutenção política faz com que as grandes empresas sejam os grandes agentes do capitalismo monopolista. $\mathrm{O}$ dinheiro se concentra em grandes volumes nas empresas e torna-se fonte de poder político.

Quando as grandes oligarquias veem seu poder ou suas fontes de lucros ameaçados (pelo investimento em educação, moradia, assistência), poderosas instâncias de resistência são mobilizadas. Uma delas é a substituição do governo democrático pelo autoritário. As classes privilegiadas dominam os instrumentos de coação e lançam mão de suas artimanhas. Vale lembrar que o poder político é financiado por elas. Em países com histórico democrático há preferência por pequenas concessões que não ferem a ordem estabelecida e reduz a fúria dos opositores. Já em países com histórico autoritário há a ascensão (por vias democráticas ou não) de regimes fascistas.

Baran e Sweezy (1966) destacam que uma das formas para que investimentos públicos não alterem os privilégios das elites é direcionando-os para fontes que não apresentem riscos e que fortalecem o controle e a coesão social. Os gastos militares e o imperialismo oferecem uma saída para tal situação. Entretanto, a militarização estimula forças reacionárias e irracionais na sociedade, inibindo e matando o que é progressista e humano. A militarização da sociedade leva ao respeito cego à autoridade, atitudes de docilidade e conformismo. Elas são pregadas e impostas. A discordância é tratada como falta de patriotismo ou traição (ADORNO, 2006). A militarização traz à tona os elementos fascistas e totalitários da sociedade capitalista.

Baran e Sweezy (1966) destacam que o capitalismo monopolista gera a tendência de ciclos de estagnação e depressão. A constante racionalização e aumento da produção por empresas gigantes não é acompanhada de alterações na organização social e eliminação da miséria. Uma das consequências da irracionalidade do todo é o deserto ideológico, característico desse sistema.

Em relação ao trabalho, Marcuse (1973) destaca que ele se torna labuta e estupefaciente. Isso ocorre quanto mais real se demonstra a sua não necessidade. Os modos de descanso mitigam e prolongam a estupefação. As liberdades acabam por se mostrar decepcionantes, tais como: consumo do inútil, livre competição a preços administrados, uma imprensa livre que se autocensura.

Baran e Sweezy (1966) ressaltam que é ideologia acreditar na livre iniciativa e na democracia do capitalismo monopolista. Ele preconiza uma pequena oligarquia com enorme poder econômico que controla a tomada de decisões pela manipulação do aparato político e cultural.

Marcuse (1973) ressalta que nesse contexto há a sufocação da necessidade de libertação; ele mantém a sociedade sob suas bases irracionais. O fim das lutas entre operários e elites ocorre mediante a assimilação dos primeiros ao mundo do consumo. Tal elemento é um dos sintomas de tal sufocação:
Essa mediação histórica ocorreu na consciência e na ação política das duas grandes classes que se defrontavam na sociedade: a burguesia e o proletariado. No mundo capitalista, ainda são as classes básicas. Contudo, o desenvolvimento capitalista alterou a estrutura e a função dessas duas classes de tal modo que elas não mais parecem ser agentes de transformação histórica. Um interesse predominante na preservação e no melhoramento do status quo institucional une os antigos antagonistas nos setores mais avançados da sociedade contemporânea (MARCUSE, 1973, p. 16).

Dessa maneira, a produtividade serve como elemento de coerção e coesão social, impondo-se acima de interesses individuais e grupais. O governo, no capitalismo monopolista, reafirma seu poder e se desenvolve a partir da mobilização, organização e exploração com êxito da produtividade técnica e mecânica à disposição na sociedade. Assim, é inútil falar de liberdade (política, econômica e intelectual) mediante o totalitarismo do sistema. Esse deixa à mostra suas diversas irracionalidades, como a capacidade de conter a transformação social. Isso conduz a uma das grandes contradições do capitalismo monopolista que é a intensificação dos preconceitos e, consequentemente, o aumento da discriminação e segregação. O nazismo é uma dessas manifestações.

\section{2 - Consequências das transformações do capitalismo na formação do indivíduo}

\section{A. Características da formação do indivíduo no capitalismo liberal}

Segundo Marcuse (1998a), a ideologia liberal, que deu sustentação à configuração do capitalismo liberal, preconizava a transformação do modelo burguês de indivíduo e dos valores atribuídos a este como unidade fundamental e fim da sociedade. A autonomia seria a característica genuína do indivíduo de acordo com tendências políticas, econômicas e religiosas dos séculos XVI e XVII. O indivíduo deveria ser portador de certos padrões e valores fundamentais que nenhuma autoridade externa deveria desrespeitar. Tais padrões e valores referiam-se a formas de vida, tanto social como pessoal, que são a verdade da existência individual. Cada indivíduo seria portador de razão e capaz de encontrar suas verdades por meio da liberdade de pensamento, capacidade de ação e transformação da realidade. Aos indivíduos a sociedade deveria liberdade e a eliminação todas as restrições à sua linha de ação racional. Tal concepção é denominada de individualismo (que apregoa a busca do interesse próprio guiado pela razão individual ou pensamento autônomo). O individualismo é considerado a base do capitalismo liberal dos séculos XVIII e XIX.

Marcuse (1998a) destaca, ainda, que o interesse próprio racional da sociedade não coincidia com o interesse próprio imediato do indivíduo. O indivíduo, para alcançar os seus interesses, dependeria dos padrões e demandas da ordem social dominante. Tais padrões e demandas seriam instituídos por autoridades externas e não pelo pensamento autônomo ou a consciência. 
No período liberal do capitalismo, o indivíduo era colocado contra a sociedade, buscando superar todas as imposições e impor os próprios interesses racionais. Isso levava a um estado de constante vigilância, apreensão e crítica, que rejeitava o que não fosse verdadeiro nem justificado pela livre razão. Em uma sociedade com grandes contradições, a possibilidade da crítica e análise racional dos próprios interesses constituía a possibilidade de inquietação e oposição. Portanto, a liberdade estava associada à crítica aos padrões vigentes, procura de padrões verdadeiros e tentativa de realização (mesmo que confrontando toda a sociedade).

Para que o indivíduo realizasse sua racionalidade seria necessário um ambiente social e econômico adequado, que atraísse indivíduos cujas condutas e realizações sociais fossem seu próprio trabalho. A sociedade liberal era ideal à racionalidade individualista, pois, pela livre concorrência, o indivíduo transformava (pelos seus feitos e ação) o produto de seu trabalho em parte das necessidades da sociedade. Assim, o produto do trabalho de cada indivíduo se tornaria marca de sua individualidade. Adorno (2006) destaca algumas qualidades do indivíduo em seu molde liberal: este é filho de uma sociedade liberal, competitiva, individualista e está condicionado a se manter como unidade independente e autossustentável, sendo continuamente advertido de que deve ser duro e prevenido contra rendição.

\section{B. Características da formação do indivíduo no capitalismo monopolista}

No capitalismo monopolista, a contraposição entre indivíduo e sociedade (que visava a uma reforma militante da segunda com base nos interesses do indivíduo) se desfaz pela forma como o sistema passa a se organizar. A oposição é substituída pela adesão. Tal processo prepara e justifica o afastamento do indivíduo da sociedade. A autonomia, tema essencial da ideologia liberal, passa a ser vista como assunto privado em vez de público, um elemento de retirada em vez de agressão. A contenção e a resignação tornam-se cada vez mais presentes na filosofia individualista, ilustrando o ocaso do modelo de indivíduo liberal.

Os elementos expostos têm relação direta com a formação do indivíduo, ao ponto de os autores da primeira geração da Escola de Frankfurt anunciarem o ocaso deste a partir do capitalismo monopolista e das alterações políticas, sociais, econômicas e culturais geradas (HORKHEIMER, 2010; ADORNO, 1971, 1991; MARCUSE, 1998b, 1999).

Baran e Sweezy (1966), mesmo não pertencendo a tal referencial teórico, percebem os sintomas da derrocada da individualidade. Entre outros elementos, eles apontam para a desintegração da família burguesa, tendo como decorrência a crescente solidão e miséria no capitalismo monopolista. A solidão não pode ser superada, transformando cada um em uma partícula na multidão pela necessidade de adesão. A miséria de estar só e o horror da companhia de terceiros produzem uma atitude de ambivalência entre o envolvimento e o alheamento. Dessa maneira, são criados mecanismos para disfarçar a falta de relacionamento e interesse emocional entre as pessoas (como as redes sociais na contemporaneidade). Adorno $(1991,2006)$ propõe que a nova organização do capitalismo leva os indivíduos a estados regredidos de consciência, atrelando tal concepção ao narcisismo, uma das descobertas de Freud.

Baran e Sweezy (1966) sugerem que a crescente racionalização das esferas econômicas e humanas levou ao desaparecimento de qualquer finalidade significativa em relação à vida. Isso ocorre tanto socialmente como individualmente. $\mathrm{O}$ trabalho perde o seu sentido, transformando-se em labuta, e o tempo livre causa aborrecimento devido ao ar de inutilidade de que a vida se reveste.

A sexualidade, a partir do fracasso do prazer no trabalho e em outras esferas da vida, no capitalismo monopolista torna-se uma das principais formas de satisfação, mas cuja finalidade não pode ser atingida em uma sociedade em que os padrões morais humanos e os meios de satisfação encontram-se aquém do que poderiam e até mais regredidos do que em outros momentos da história.

O indivíduo torna-se um mero apêndice da sociedade, um átomo social do qual a totalidade enlouquecida pode abrir mão (HORKHEIMER, 2010; ADORNO, 1991, 2006; MARCUSE, 1973, 1998b). Devido à crescente especialização e racionalização dos processos sociais, o indivíduo pode ser comprimido em esquemas redutores impostos de fora. $\mathrm{O}$ resultado de tal processo não pode ser chamado de individualidade ou subjetividade, mas um produto humano padronizado, racionalizado e sistematicamente controlado por meio de levantamentos estatísticos. As reações ditas individuais se tornam cada vez mais automáticas e previsíveis. Horkheimer (2010) chega ao ponto de afirmar que toda defesa da individualidade e unicidade dos homens cai por terra diante de questionários ou testes que englobam a existência da maioria dos homens.

Para Baran e Sweezy (1966) um dos sintomas da "extinção" do indivíduo é o aborrecimento causado pelas horas livres, que podem ser mais opressivas do que o trabalho, de tal maneira que o tempo é preenchido com diversas trivialidades ou encontros sociais vazios. A vida e o tempo livre tornam-se ociosidade ou trivialidade. As conversas reduzem-se aos bate-papos entre amigos.

Horkheimer e Adorno (1985) "criam" o conceito de Indústria Cultural para denotar como até mesmo nas horas livres o trabalho alienado e o totalitarismo da cultura invadem a vida. Tal processo destitui de sentido a divisão entre as esferas pública e privada e prepara os indivíduos para a adesão, consumo e labuta.

Marcuse (1973) destaca que um dos aspectos mais perturbadores do capitalismo monopolista é o caráter racional de sua irracionalidade. A produtividade, eficiência, capacidade para aumentar e disseminar comodidades, transformar resíduo em necessidade e a destruição em construção fazem com que tal sistema transforme o mundo objetivo em uma extensão da mente e do corpo humanos. Isso torna questionável até a própria noção de alienação, pois os indivíduos conseguem se reconhecer em suas mercadorias. O controle social do indivíduo se dá na produção de novas 
necessidades e altera o mecanismo que ata o indivíduo à sua sociedade: no liberalismo a oposição e no capitalismo monopolista a assimilação e adesão. A sociedade atende às necessidades do indivíduo pela forma como está organizada e reduz a possibilidade de oposição:

Essa repressão, tão diferente daquela que caracterizou as etapas anteriores, menos desenvolvidas, de nossa sociedade, não opera, hoje, de uma posição de imaturidade natural e técnica, mas de força. As aptidões (intelectuais e materiais) da sociedade contemporânea são incomensuravelmente maiores do que nunca dantes - significando que o alcance da dominação da sociedade sobre o indivíduo é incomensuravelmente maior do que nunca dantes. A nossa sociedade se distingue por conquistar forças sociais centrífugas mais pela Tecnologia do que pelo Terror, com dúplice base numa eficiência esmagadora e num padrão de vida crescente (MARCUSE, 1973, p. 14).

Adorno (1991) destaca a desproporção no campo social entre as grandes empresas, o governo, o exército e as instituições com o indivíduo. Perante a grandeza das instituições são necessárias forças sobre-humanas para se opor. Até mesmo a sobrevivência se torna impossível fora do sistema. A vida reduz-se à submissão para a autoconservação. Para Marcuse (1998a), ao manipular a máquina o homem aprende que a obediência é o único meio de se obter resultados desejados. Portanto, a adaptação ao aparato é a única saída, e ela se impõe sobre a racionalidade individualista, preconizada no período liberal do capitalismo.

\section{3 - Formação do indivíduo na contemporaneidade}

O modelo de indivíduo das revoluções burguesas (pautado no modelo liberal) torna-se obsoleto no capitalismo monopolista. Tudo contribuiu para transformar os instintos, desejos e pensamentos humanos em canais que alimentam o aparato industrial. $\mathrm{O}$ sistema produtivo impõe suas exigências econômicas e políticas à defesa e à expansão do tempo de trabalho no tempo livre. A sociedade contemporânea é totalitária pela forma como organizou sua base tecnológica, pois esta invade todas as esferas da vida humana (MARCUSE, 1973).

Um dos elementos destacados por Horkheimer (2010) para o totalitarismo da sociedade sobre o indivíduo é a alteração da racionalidade. A razão se tornou independente do indivíduo. Ela não se pauta por elementos humanos, mas relacionados ao funcionamento do aparato e manutenção da ordem. A explosão do nazismo na Alemanha é um dos exemplos mais contundentes de tal manifestação.

No mesmo sentido, Marcuse (1998a) destaca que os indivíduos, na atual sociedade, são despidos de sua individualidade. Isso não ocorre pela coerção externa, mas pela própria racionalidade sob a qual vivem. O aparato ao qual o indivíduo deve adaptar-se é tão racional que o protesto e a libertação individual parecem, além de inúteis, absolutamente irracionais.

A racionalidade individualista do período liberal transforma-se em racionalidade tecnológica. Segundo o autor, esta estabelece padrões de julgamento e fomenta atitudes que predispõem os homens a aceitar e introjetar os ditames do sistema. A eficiência submissa é a mais perfeita ilustração da estrutura da racionalidade tecnológica. Com isso, a razão se transforma: de força crítica para elemento de ajuste e submissão. Assim, a razão perde autonomia ao mesmo tempo em que os pensamentos, sentimentos e ações da humanidade são moldados pelas exigências técnicas do aparato que ela mesma criou. O túmulo da razão é o sistema de controle, produção e consumo padronizado que acaba por padronizar os homens e a racionalidade.

Para Marcuse (1998a), no capitalismo monopolista os padrões (de consumo, racionalidade, atitudes e individualidade) passam a ser ditados de fora aos indivíduos, que devem se adequar ao aparato. A liberdade destes reduz-se à seleção dos meios mais adequados para alcançar uma meta determinada exteriormente.

Os desafios lançados pelas alterações na formação do indivíduo nas transformações do capitalismo são temas extremamente importantes à Psicologia que se diz crítica.

Os autores da primeira geração da Escola de Frankfurt sugerem, a partir de suas reflexões, que a liberdade do sujeito econômico no capitalismo liberal foi submersa na eficiência, e a racionalidade se tornou poder social. Ao indivíduo não resta outra possibilidade senão a de adaptação sem ressalvas para a manutenção de sua existência, que se reduz à autoconservação. No capitalismo monopolista as condições que formam a individualidade se rendem às condições que tornam a individualidade desnecessária (ADORNO, 1991, 2006). A padronização em todas as esferas demonstra que a criatividade e a originalidade individuais tornam-se desnecessárias. Com o fim da era liberal, estas foram desaparecendo do domínio da produção material e tornando-se cada vez mais propriedade exclusiva das elevadas atividades intelectuais, tendendo a desaparecer destas devido à cultura de massas.

Destaca-se que as reflexões dos frankfurtianos não apontam a nostalgia pelo modelo liberal de indivíduo. Elas indicam possibilidades negadas pelo "desenvolvimento" e que só podem ser realizadas pela superação do capitalismo e de sua racionalidade/irracionalidade. Apenas a subversão da própria ordem objetiva poderia "libertar" as forças negadas no desenvolvimento de tal sistema (MARCUSE, 1999).

As reflexões de Adorno, Marcuse e Horkheimer, apesar de terem sido escritas em meados do século passado, permanecem extremamente atuais na contemporaneidade. Algumas críticas de tais autores se tornam fundamentais à compreensão do atual estágio de desenvolvimento do capitalismo (financeiro), tais como: anacronismo do modelo burguês de individualidade, enfraquecimento de capacidades críticas e "fusão" entre interesses individuais e coletivos. Tais elementos podem ser considerados sintomas da pertinência de tais contribuições. Ainda mais no momento do "reaparecimento" das massas totalitárias e fascistas por meio de seu controle tecnológico contemporâneo. Vale destacar que o fascismo não pode ser superado no capitalismo por ser decorrente da própria racionalidade de tal sistema produtivo.

O desenvolvimento tecnológico das últimas décadas potencializou processos que sempre permaneceram latentes na sociedade capitalista. As últimas eleições 
presidenciais nos EUA e no Brasil demonstram como algoritmos de computadores podem prever facilmente o comportamento dos "indivíduos". A novidade de tal processo é a utilização política eleitoral de tecnologia anteriormente utilizada para campanhas publicitárias. Tal processo ocorre com o uso maciço de tecnologias publicitárias utilizando-se de conhecimentos sociológicos e psicológicos. Soma-se a isso, na contemporaneidade, tecnologias de controle da navegação na internet.

Nas campanhas publicitárias é feita a segmentação da população em determinados perfis (de acordo com sites visitados, comportamento em redes sociais, etc.) e envio de mensagens eletrônicas "personalizadas" de acordo com "interesses" pessoais. Pode-se dizer que o mesmo procedimento foi utilizado para eleições presidenciais, tanto no Brasil como nos EUA. A tecnologia moderna refinou as estratégias dos agitadores fascistas transmitidas por rádio e TV e descritas por Adorno (2006). O documentário recente denominado "Driblando a democracia: como Trump venceu" (online) demonstra como foi utilizado controle tecnológico das redes sociais e algoritmos de computadores para vencer as últimas eleições presidenciais americanas. Ele aponta como o comportamento político dos eleitores foi meticulosamente estudado e compilado por meio das redes sociais. Pelo uso de algoritmos, tais informações foram transformadas em perfis padronizados de eleitores. Cada segmento estava relacionado à sensibilidade sobre determinadas temáticas, tais como: porte de armas, defesa da propriedade privada, liberdades civis de minorias, corrupção, etc.

Mensagens "personalizadas" que apelavam para medos inconscientes de determinados segmentos eram encaminhadas de forma privada no "Facebook". E se nos EUA tal estratégia foi arquitetada pelo uso do Facebook, no Brasil houve a preferência pela criação de grupos temáticos no WhatsA$p p$. Tal elemento é de conhecimento popular por meio de reportagem no jornal "Folha de São Paulo" (MELLO, 2018, online). Todavia, a reportagem não traz maiores informações sobre a segmentação dos perfis de mensagens.

Além da segmentação de perfis, se percebe também a produção industrial e massificada de notícias falsas. Essas foram distribuídas de acordo com perfis de sensibilidade a temáticas específicas. Tal processo fez com que defensores da irracionalidade se travestissem de defensores de interesses coletivos. Ao mesmo tempo, questiona-se a possibilidade de escolhas livres pelos indivíduos. Não se devem considerar as pessoas que foram manipuladas como agentes meramente passivos. Havia, mesmo que inconscientemente, em cada indivíduo algo que os fazia aderir a tais mensagens (ADORNO, 1991, 2006).

As reflexões da primeira geração da Escola de Frankfurt estão voltadas para os meios de comunicação de massa do período de seus escritos. Em tal período as mensagens dos agitadores fascistas eram transmitidas pelas ondas do rádio e da TV. Tais mensagens podiam ser alvo de controle e crítica social. Ao mesmo tempo, as mensagens deveriam possuir determinado grau de generalidade para atingir o maior número de indivíduos. Além disso, corriam o risco "de se perderem no ar".
Atualmente, a mensagem é encaminhada de modo privado, atingindo inconscientemente e de forma "personalizada" o indivíduo, de acordo com seu perfil. Tal fato só se tornou possível devido aos avanços tecnológicos usados contra a humanidade e na defesa de interesses escusos. Acrescenta-se que tais mensagens, por serem transmitidas por aplicativos de celulares e/ou computadores, apresentam certa dificuldade de controle social e político.

A partir do exposto, pode-se inferir que as contribuições dos frankfurtianos tornaram-se anacrônicas quanto aos meios (tecnológicos) pelos quais são transmitidas, mas são extremamente atuais quanto aos seus efeitos psicossociais. Além disso, processos de produção industrial e massificada de indivíduos e subjetividades, descritos pelos autores, ganham contornos jamais imaginados devido ao desenvolvimento e controle tecnológico.

A possibilidade da defesa de certa autonomia frente ao todo não deve ser colocada em segundo plano. Mesmo que tal mote possua elementos ideológicos, ele deve superar seu viés liberal ainda mais em tempos do reaparecimento de movimentos totalitários. Tais movimentos, apesar das diferenças em relação aos do século passado, ainda visam à integração total dos indivíduos e tendem a desqualificar toda diferença. Portanto, o debate e a luta pelo indivíduo (único em meio ao total) em uma sociedade totalitária é também uma política pela superação do capitalismo, o futuro da humanidade, e pela própria superação da concepção burguesa de individualidade.

\section{Informações sobre o autor:}

Gustavo Henrique Carretero

(iD) https://orcid.org/0000-0002-9633-2581

(9) ttp://lattes.cnpq.br/6373778457510094

Possui graduação em Psicologia pela Pontifícia Universidade Católica de Campinas (2006), mestrado em Psicologia (Psicologia Social) pela Pontifícia Universidade Católica de São Paulo (2011)

e doutorado em Psicologia (Psicologia Social) pela Pontifícia Universidade Católica de São Paulo (2018).

\section{Como citar este artigo:}

\section{ABNT}

CARRETERO, Gustavo Henrique. Transformações do capitalismo e formação do indivíduo: contribuições da Escola de Frankfurt na análise das eleições presidenciais nos EUA e Brasil. Fractal: Revista de Psicologia, Niterói, v. 31, n. 2, p. 83-90, maio/ago. 2019. https://doi.org/10.22409/1984-0292/v31i2/5619

\section{APA}

Carretero, G. H. (2019). Transformações do capitalismo e formação do indivíduo: contribuições da Escola de Frankfurt na análise das eleições presidenciais nos EUA e Brasil. Fractal: Revista de Psicologia, 31(2), 83-90. doi:10.22409/1984-0292/v31i2/5619

\section{Referências}

ADORNO, Theodor Ludwig Wiesengrund. La revision del Psicanalisis (1942). In: HORKHEIMER, Max; ADORNO, Theodor Ludwig Wiesengrund. Sociologica II. Madrid: Taurus, 1971. p. 133-156.

ADORNO, Theodor Ludwig Wiesengrund. De la relación entre Sociología y Psicología (1955). In: Filosofia. Barcelona: Paidós, 1991. p. 135-205. 
ADORNO, Theodor Ludwig Wiesengrund. A teoria freudiana e o padrão de propaganda fascista (1951). Margem esquerda: ensaios marxistas, v. 7, p. 164-189, 2006.

BARAN, Paul A.; SWEEZY, Paul. M. Capitalismo monopolista: ensaio sobre a ordem econômica e social americana. Rio de Janeiro: J. Zahar, 1966.

CROCHIK, José Leon. Os desafios atuais do estudo da subjetividade na Psicologia. Psicologia USP, São Paulo, v. 9, n. 2, p. 69-85, 1998. http://dx.doi.org/10.1590/S010365641998000200003

DRIBLANDO a democracia: como Trump venceu [documentário]. Direção de Thomas Huchon. Paris: Spicee, 2018. (52 min.), son., color. Disponível em: http://canalcurta. tv.br/filme/?name=driblando a democracia como trump venceu. Acesso em: 22 dez. 2018.

HORKHEIMER, Max; ADORNO, THEODOR LUDWIG WIESENGRUND. Dialética do Esclarecimento (1944). Rio de Janeiro: J. Zahar, 1985.

HORKHEIMER, Max. Eclipse da Razão (1955). São Paulo: Centauro, 2010.

MARCUSE, HERBERT. Ideologia da sociedade industrial: o homem unidimensional (1964). Rio de Janeiro: J. Zahar, 1973.

MARCUSE, HERBERT. Algumas implicações sociais da tecnologia moderna (1941). In: Tecnologia, guerra e fascismo. São Paulo: UNESP, 1998a. p. 73-104.

MARCUSE, HERBERT. A Obsolescência da Psicanálise (1963). In:__ Cultura e Sociedade. Rio de Janeiro: Paz e Terra, 1998b. v. 2, p. 91-111.

MARCUSE, HERBERT. Eros e civilização: uma interpretação filosófica do pensamento de Freud (1959). 8. ed. Rio de Janeiro: Livros Técnicos e Científicos, 1999.

MELLO, Patrícia Campos. Empresários bancam campanha contra o PT pelo WhatsApp. Folha de São Paulo, São Paulo, 18 out. 2018. Disponível em: https://www1.folha.uol.com.br/ poder/2018/10/empresarios-bancam-campanha-contra-o-ptpelo-whatsapp.shtml. Acesso em: 4 dez. 2018. 